Brocar, $21(1998) 311-319$

\title{
EL SEMINARIO CONCILIAR DE LOGROÑO EN LA SEGUNDA MITAD DEL XIX
}

\author{
Marie-Hélène Buisine-Soubeyroux*
}

I. ORÍGENES Y REGLAMENTO DEL SEMINARIO

\section{Del colegio de Jesuitas al seminario}

En 1559, fue fundado en Logroño un colegio de la Compañía de Jesús que iba a ser durante numerosos años el principal foco educativo de la ciudad ${ }^{1}$. Después de la disolución de la congregación y de la confiscación de sus bienes bajo el reinado de Carlos III, a partir de 1767 , se renovaron los locales con el fin de instalar allí un seminario conciliar común a todo el obispado. Un legajo de los archivos municipales con fecha de 1774 da cuenta de la decisión tomada ${ }^{2}$. Sin embargo parece que el establecimiento no pudo iniciar su actividad antes del año de 1776 por motivos de rivalidad entre la ciudad de Logroño y las dos catedrales de Calahorra y Santo Domingo de La Calzada que hasta entonces se repartían entrambas la dirección del seminario (que funcionaría hasta $1929^{3}$ ).

Esta muy breve historia del establecimiento nos parecía imprescindible para comprender sus orígenes y también situarlo entre los establecimientos privados religiosos cuya importancia en la historia de la educación española en el siglo XIX ya no debe ponerse en duda.

* Profesora del Departamento de lengua, literatura y civilización españolas de la Universidad de SaintEtienne, Francia.

1. Para más información, veáse Armas Lerena, Noemí, "Los primeros años de la Companía de Jesús en Logroño", Brocar, n 19, 1995, pp. 65-83. También Armas Lerena, Noemí, e Ibáñez Rodríguez, Santiago, "Consecuencias políticas de la expulsión de los jesuitas. El poder del colegio de la Compañía de Jesús de Logroño y la destitución del corregidor", Berceo, $\mathrm{n}^{\circ}$ 131, 1996, pp. 127-158.

2. Archivo Municipal de Logroño, sección educación, legajo $n^{\circ} 146-8,1774$ : «Antecedentes de la instalacón del seminario".

3. Abad León, Felipe, Radiografia bistórica de Logroño a la luz del Catastro de La Ensenada, Logroño, Instituto de Estudios Riojanos, 1978, p. 207. 


\section{El reglamento interior de 1861}

El documento consultado en el archivo diocesano ${ }^{4}$ consta de seis partes, que corresponden en su mayoría a los diferentes lugares donde podían evolucionar los pensionistas según sus actividades: la capilla, la sala de estudio, el refectorio, y la sala de recreo y la huerta. Las otras dos se refieren respectivamente al traje de los alumnos y a disposiciones generales.

Durante los actos religiosos en la capilla los alumnos tenían que colocarse según su edad y su nivel de estudios ; los más jóvenes en el centro del coro, muy cerca del altar y los mayores cerca de la reja que separa el coro de la nave. Recibían la sagrada comunión únicamente los días señalados por el obispo y tenían la obligación de ayudar a la misa.

En la sala de estudio, los sitios estaban reservados según la edad. Estaba prohibido hablar y la salida había de efectuarse en silencio.

Tal regla de silencio se aplicaba también a la manera de portarse en el refectorio. Estaba prohibido en absoluto hablar cuando entraban o salían los pensionistas, y un relativo silencio ("mediano») se requeria durante las comidas acompasadas de noche por la lectura de la vida de un santo.

El rigor y la austeridad de este reglamento se traducían también por la prohibición de llevar la más mínima cantidad de alimento («ni un bocado») so pena de deber restituirla en el acto y verse expulsado definitivamente a la tercera tentativa.

Durante los momentos de descanso en la sala reservada y en la huerta, los juegos de cartas no estaban permitidos, sólo el juego de damas y la lotería se toleraban pero sin exceso. Los juegos de pelota los permitian pero habían de cesar media hora antes del final del recreo. De todas maneras cualquier manifestación excesiva de divertimiento o de alegría y por supuesto los gritos y el canto estaban absolutamente prohibidos.

El traje de los internos se componía de una sotana de paño negro y de un balandrán llevado dentro del establecimiento. Fuera tenían que llevar además de estos vestidos un sombrero de tela canal, un manteo y zapatos de pala y media con un pantalón alzado.

Siguiendo el orden de presentación de las varias rúbricas que constituyen el reglamento, las disposiciones generales trataban de las visitas y de la correspondencia, de la limpieza de las habitaciones y del aseo, de la manera de portarse por la manaña antes del principio de las clases.

Toda salida fuera del establecimiento estaba prohibida, excepto los días de "primera clase» con autorización de una persona responsable. La vuelta había de efectuarse obligatoriamente a las cuatro. Las visitas, también muy reglamentadas, sólo habían de efectuarse entre las diez y las diez y media de la mañana y entre las cuatro y cinco de la tarde, los días de clase; durante los otros días estaban previstas entre las diez y las once y media. Sólo los sacerdotes podían entrar en las habitaciones de los seminaristas que de ninguna manera podían recibirse entre sí, tampoco podían abrir su ventana cuando estaban en la habitación, y mucho menos dirigir la palabra a quien

4. Archivo Diocesano de Logroño, fondo seminario, caja n ${ }^{\circ}$ 133: «Disposiciones por las que se regirán los señores internos y que se observarán con todo rigor una vez que estén aprobadas por el Muy llustre Señor Gobernador Eclesiảstico de la Diócesis Sede Vacante». 
estuviese en la calle. Cada pensionista era el único responsable de los deterioros que podian ocurrir en su habitación y tenía que apagar la luz a las diez de la noche.

Toda correspondencia estaba depositada en un buzón reservado para este uso, y si un pensionista necesitaba hacer compras en la ciudad, tenía que preparar una lista que confiaba por la mañana en el momento del desayuno al criado encargado de ellas. A la hora del rosario, todos los pensionistas iban por su pedido y lo pagaban al señor rector.

En lo que se refiere a la higiene y a la limpieza, cada uno debía lavarse y hacer su cama por la mañana antes de las ocho; la limpieza completa de la habitación era obligatoria los sábados después de la comida. Se afeitaban los miércoles y los sábados desde las diez hasta las once menos cuarto. Por fin, estaba prohibido fumar sin la autorización del señor rector.

Entre otras medidas estrictas, estaba prohibida la entrada a la cocina y los pensionistas sólo tenían derecho a ir por agua en días y horas marcados con el permiso del director espiritual.

En cuanto a las horas de reunirse antes de las clases, por la mañana, todos los alumnos lo hacían delante de la puerta del rector, cuando tocaba la campana. Por la tarde, todos se ponían en fila delante de la puerta del despacho de uno de los profesores, excepto los alumnos de quinto y sexto año cuyo sitio de reunión podía variar.

Podemos preguntarnos si este reglamento muy estricto, impuesto a los seminaristas internos durante tres o siete años según la carrera elegida, reflejaba verdaderamente la realidad o sólo era la expresión de una voluntad.

\section{Carreras propuestas y MATERIAS ESTUDiadas}

\section{Las carreras en 1860-1861}

En cuanto a 1860-1861, hemos podido trabajar con dos listas de alumnos clasificados por carreras y años de estudio, con mención de las materias. Según esos documentos, tres carreras, siendo las dos primeras las herederas directas de las cátedras que existian en el colegio de jesuitas ${ }^{5}$, estaban propuestas a los seminaristas ${ }^{6}$.

La primera, que duraba tres años, se llamaba Filosofía. Parecía destinada a alumnos que deseaban seguir una enseñanza secundaria general, aunque era más corta que en el instituto de segunda enseñanza (tres años en vez de cinco), y el estudio de la religión constituía gran parte de ella.

La segunda, sin duda reservada a los seminaristas que se preparaban al sacerdocio y titulada Teología, se prolongaba siete años. Se trataba de estudiar la Escritura Sagrada y la Teología.

La tercera, instituida en 1849 , en virtud de una prerogativa concedida a los obispos y que trataba de los cuadros de enseñanza de los seminarios, se dirigía a los alumnos

5. Armas Lerena, Noemi, art. cit., p. 69.

6. Archivo Diocesano de Logroño, fondo seminario, caja $n^{\circ} 44-3,1860-1861$ : «Lista de los alumnos tanto internos como externos que han probado sus respectivos años de Sagrada Teología y Filosofía en este seminario conciliar». Caja n 46,1860-1861 : "Nómina de los gramáticos del seminario conciliar». 
gramáticos que podían preparar en el establecimiento, o en casa, de manera privada, los exámenes que correspondian a los cuatro años de Latín y Humanidades, después de los cuales estaban admitidos a seguir los cursos de una de las dos asignaturas.

A cada año de cada una de las dos primeras carreras correspondía el estudio de una o varias asignaturas diferentes:

Primer año de Filosofía: Lógica, Ontología, Cosmología y Psicología empírica.

Segundo año de Filosofía: Física, Química, Aritmética y Algebra.

Tercer año de Filosofía: Etica, Religión y Teodicea.

Primer año de Teología: De Religione et de Locis Theologicis.

Segundo año de Teología: De Deo Uno, Trino, Creatore et Incarnato.

Tercer año de Teología:Teología Moral y Dogmática en la parte sacramental.

Cuarto año de teología: como durante el segundo año.

Quinto, sexto y séptimo años de Teología: Hermeneútica y Oratoria Sagrada.

Después de observar el contenido de los documentos se nota la especialización de cada año de estudio, tanto en Teología como en Filosofía, teniendo allí los alumnos en su programa un máximo de cuatro asignaturas distintas.

No hemos podido averiguar, por no tener documentos apropiados, si se trataba de una característica constante de los estudios en el seminario. Para ser totalmente afirmativa en cuanto a tal especialización hubiera sido necesario conocer también el número de horas reservadas al día o a la semana a cada asignatura.

Poseemos parte de estas informaciones para un año posterior. Las hemos examinado como complementarias.

El cuadro de enseñanza de $1878-1879^{7} \mathrm{del}$ seminario del año académico de 1878 1879 se presenta bajo forma de un cuadro $\left(\mathrm{n}^{\circ} 1\right)$ de cuatro columnas que dan las siguientes indicaciones: materia, días, horas del principio de las clases y apellido del profesor.

Conocemos bien la composición del equipo administrativo y pedagógico para ciertos años correspondientes al período estudiado.

Cuadro 1. Cuadro de enseñanza para el curso académico de 1878-1879 en el seminario de Logroño

$\begin{array}{llrl}\text { Materias } & \text { Días } & \text { Horas } & \text { Profesor } \\ \text { Instituciones } & & 11 & \text { Nicanor Ibarra } \\ \text { económicas } & \mathrm{D} & 10 & \text { Idem } \\ \text { Escritura sagrada } & \mathrm{D} & 9 & \text { Rector } \\ \text { Oratoria sagrada } & \mathrm{S} & 10 & \text { Nicanor Ibarra } \\ \text { Patrología } & \mathrm{S} & 9.30 & \text { Rector } \\ \text { Teología dogmática } & \mathrm{D} & 10 & \text { Magistral } \\ \text { Lugares teológicos } & \mathrm{D} & & \end{array}$

7. Archivo Diocesano de Logroño, fondo seminario, caja ${ }^{\circ} 180$. 


$\begin{array}{llrl}\text { Teología moral } & \mathrm{D} & 14.30 & \text { Rector } \\ \text { Historia eclesiástica } & \mathrm{D} & 11 & \text { Magistral } \\ \text { Física y química } & \mathrm{D} & 14.30 & \text { José Muñoz } \\ \text { Matemáticas 1er año } & \mathrm{D} & 10 & \text { Eduardo Pérez } \\ \text { Matemáticas 2do año } & \mathrm{D} & 14.30 & \text { Idem } \\ \text { Filosofía moral } & \mathrm{D} & 10 & \text { Santiago Lapeña } \\ \text { Lógica y } & \mathrm{D} & 10 & \text { Valentín Mendiondo } \\ \text { metafísica } & & 14.30 & \\ \text { Retórica y poética } & \mathrm{D} & 10 & \text { Matías Díez } \\ & & 14.30 & \\ \text { Latín 1er año } & \mathrm{D} & 10 & \text { Hilario. Loza } \\ \text { Latín 2do anõ } & & 14.30 & \\ \text { Historia y geografia } & \mathrm{D} & 16 & \text { Idem } \\ \text { Religión y moral } & \mathrm{J} \mathrm{D} & 8 & \text { Director espiritual } \\ \text { Canto llano } & \mathrm{D} & 10.30 & \text { Cipriano Bermejo }\end{array}$

\section{PRofesores y ALUMNOS}

\section{Los profesores}

El equipo de dirección se componía de un rector y de un vicerrector. En 1860, eran Juan Francisco Ruiz de la Cámara y Santiago Palacios y Cabello. Los asistía un eclesiástico mayordomo, Bernardino Martínez. Cobraban los salarios siguientes: el rector, por una hora de clase diaria, 3.600 reales ; el vicerrector, encargado de dos horas de clases diarias, 3.600 reales ; el director mayordomo, por una hora de clase diaria, 3.160 reales. En cuanto a los profesores, recibían 2.160 reales cuando daban una clase diaria y de 3.000 a 3.600 reales por dos horas ${ }^{8}$. La cantidad poco elevada de estos salarios se explica sin duda porque se trataba de gratificaciones cobradas por sacerdotes además de su remuneración principal.

En 1860 se añadían al equipo educativo propiamente dicho cinco criados, cuatro hombres y una mujer: Eusebio Pascual Pinilla (de 48 años), Gumersindo Fernández Méndez (de 32 años), Marcial Varilonga Oribe (de12 años) y Rosa Saenz Viñola (de 59 años).

\section{Los alumnos}

\section{Las diferentes categorías}

Hemos visto que los alumnos podían seguir dos carreras principales diferentes. Los documentos pues los designaban como filósofos o teólogos.

A esta primera calificación de orden pedagógico se añadían otras de orden económico.

8. Ibid. 
La mayoría de los alumnos eran pensionistas (o «porcionistas»), pagaban, al principio del período estudiado, cinco reales al día.Algunos (cuatro en 1845-1846 por ejemplo) gozaban de media beca. Los demás eran becarios dispensados de cualquier contribución. Las becas tenían dos orígenes: unas las atribuía directamente el establecimiento a los alumnos más pobres ("beca de gracia") a cambio de tener que efectuar labores domésticas, por eso los llamaban «fámulos». Las otras becas las financiaban ricos bienhechores privados, por ejemplo las ocho becas pagadas con el legado de $\mathrm{P}$. Fernández Balmaseda, en los años de 1844-1845 y de 1845-1846, que representaban 11.255 reales, el primer año, y 9.490 , el segundo'.

Por fin, una de las características del establecimiento era la división entre los alumnos internos y externos (para los diferentes años de estudio en 1860-1861, veáse el cuadro $\mathrm{n}^{\circ} 2$ ). En cuanto a la carrera de Latín y Humanidades, los alumnos considerados como externos recibían una enseñanza doméstica ${ }^{10}$. Tal posibilidad se ofrecía también a los alumnos del instituto y podemos preguntarnos si el obispado no la había instaurado (a partir de 1849) para competir con el recién creado establecimiento público.

Cuadro 2. Alumnos internos y externos según la carrera y el año cursados

$\begin{array}{llcc}\text { Año } & & \text { Internos } & \text { Externos } \\ \text { Filosofía } & \text { ler año } & 22 & 23 \\ & 2^{\circ} & 15 & 16 \\ \text { Teología } & \text { er } & 17 & 11 \\ & 1 \text { er año } & 4 & 20 \\ & \text { 2do } & 11 & 10 \\ & \text { 3er } & 12 & 8 \\ & \text { 4to } & 9 & \\ \text { 5to } & 14 & \\ \text { Latín y Humanidades } & \text { 6to } & 8 & 13 \\ & \text { 7mo } & 1 & 7 \\ & 1 \text { er año } & 2 & 8 \\ & \text { 2do } & 5 & 117 \\ & \text { 3er } & & \end{array}$

\section{El alumnado}

Presentamos en el cuadro $n^{\circ} 3$ la evolución del alumnado del seminario de 1833 a 1870 .

9. Archivo Diocesano de Logroño, fondo seminario, caja $\mathrm{n}^{\circ} 44,1833$ a 1846.

10. Sobre enseñanza doméstica, ver : Ley Moyano, 2 da sección, Título III, en Historia de la educación en España II. De las Cortes de Cádiz a la Revolución de 1868, Prólogo de Manuel Puelles Benítez, Madrid, MEC, Breviarios de Educacion, 1985, p. 275. 
Cuadro 3. Alumnado del seminario de Logroño de 1833 - 1834 a $1869-1870$

$\begin{array}{lc}\text { Años } & \text { Alumnado } \\ 1833-1834 & 179 \\ 1834-1835 & 185 \\ 1835-1836 & 209 \\ 1850-1851 & 140 \\ 1860-1861 & 235 \\ 1863-1864 & 287 \\ 1865-1866 & 246 \\ 1867-1868 & 315 \\ 1868-1869 & 185 \\ 1869-1870 & 176\end{array}$

Aunque no alcanzó el número de alumnos de otros seminarios de la misma época, como el de Orense que contaba con 511 alumnos (61 internos y 450 externos) en $1858^{11}$, el seminario de Logroño constituyó a lo largo de todo el período estudiado un establecimiento importante por el alumnado que no dejó de acoger. En vez de disminuir en la segunda mitad del siglo XIX, después de la creación del instituto, el número de alumnos conoció una progresión relativamente regular que corresponde a la del instituto hasta 1868 , lo que otra vez puede sugerir cierta rivalidad entre los dos establecimientos: 140 alumnos en el seminario y 130 en el instituto en 1850-1851, 235 por 243 en 1860-1861, 246 por 252 en $1865-1866$ y 315 por 259 en 1867-1868. Pero la baja señalada a partir de 1868 es más precoz y mucho más importante que la del instituto: 185 seminaristas por 332 alumnos del instituto en 1868-1869, y 176 por 303 en 1869-1870. El primer establecimiento víctima de la política del período revolucionario a nivel local bien parece ser el seminario.

\section{La edad de los alumnos}

Cuadro n4: Edad de los alumnos del seminario de Logronõ (1860-1861)

$\begin{array}{lc}\text { Edad } & \text { Número de Alumnos } \\ 25 \text { ans } & 1 \\ 24 & 1 \\ 23 & 9 \\ 22 & 4 \\ 21 & 11 \\ 20 & 8 \\ 19 & 8 \\ 18 & 15 \\ 17 & 16 \\ 16 & 11 \\ 15 & 8 \\ 14 & 7 \\ 13 & 5 \\ \text { Total } & 104\end{array}$


El único documento que nos ha permitido evaluar la edad media de los seminaristas es el censo de 1860 en el cual aparece una lista de 98 internos, con sus profesores y en el que hemos podido encontrar también a seis externos que vivían en su familia, o sea una muestra de 104 alumnos.

Según el cuadro $n^{\circ} 4$ la edad media es bastante elevada, superior a los diez y ocho años y el abanico es relativamente abierto, de trece a veinticinco años. Las dos terceras partes de los alumnos ( 69 de 104) tienen entre diez y seis y veintiún años y los menores de diez y seis años apenas son más numerosos (20 entre 104, o sea el 19,23\%) que los mayores de veintidós años (quince alumnos, o sea el 14,42\%, tienen entre veintidós y veinticinco años).

\section{El origen sociogeográfico de los alumnos}

Para determinar el origen sociogeográfico de los seminaristas y comprender mejor el papel y la implicación del seminario en la sociedad de Logroño en 1860-1861, hemos utilizado la lista de los archivos del obispado ya explotada a otros niveles.

Nos hemos encontrado frente a 235 casos repartidos entre nueve provincias (veáse cuadro $\mathrm{n}^{\circ}$ ) entre los cuales el 70\% (166 alumnos) son oriundos de Logroño.

Cuadro 5. Provincias de naturaleza de los alumnos del seminario de Logroño (1860 - 1861)

$\begin{array}{lc}\text { Provincias } & \text { Número de alumnos } \\ \text { Logroño } & 166 \\ \text { Navarra } & 25 \\ \text { Alava } & 17 \\ \text { Burgos } & 10 \\ \text { Vizcaya } & 7 \\ \text { Soria } & 7 \\ \text { Cáceres } & 1 \\ \text { León } & 1 \\ \text { Madrid } & 1 \\ \text { Total } & 235\end{array}$

La comparación con los alumnos del instituto subraya la relativa importancia de los que vienen de otra provincia (casi el 30\%) mientras sólo alcanzan el $20 \%$ en el otro establecimiento.

Dos provincias, vecinas de la Rioja, Navarra y Alava, proporcionan por sí solas cerca del $18 \%$ de los seminaristas.

Ahora si consideramos a los 166 alumnos oriundos de la Rioja (cuadro ${ }^{\circ} 5$ ) constatamos que el reclutamiento se concentra en cinco de los nueve distritos de la provincia: la parte céntrica de la provincia y el alto valle del Ebro (distrito de Logroño, Nájera y Haro), la zona de Arnedo y también la sierra de Cameros que envía por sí sola a 21 alumnos. Se notará en cambio la ausencia total de alumnos oriundos de Alfaro y la leve representación de los distritos de Cervera y Calahorra, este último caso se explica sin duda por la presencia en esta ciudad de un anejo del seminario de Logroño. 
La capital provincial sólo proporciona el 14\% del número de alumnos del seminario, porcentaje muy inferior al del instituto y el conjunto de las capitales de distrito sólo reúne a 41 alumnos, menos de la cuarta parte del total, mientras que veintisiete pueblos de menos de quinientos habitantes envían a treinta y ocho alumnos (cerca del $28 \%$ del número de alumnos). Estas cifras confirman el carácter fuertemente rural del reclutamiento del establecimiento.

El pequeño número de alumnos oriundos de la ciudad de Logroño no constituye una muestra bastante importante para autorizar conclusiones sobre el origen y la pertenencia social de las familias. Se notará sin embargo que dos de los ocho alumnos calificados de «pobres» en la lista de 1860-1861 son vecinos de Logroño.

Uno, Benito Rubio González (de 14 años) es hijo de un panadero, Antonio Rubio Fernández, que pagaba 42 reales de cuota en 1852. Otro, Félix Vázquez Rivas (de 15 años) es hijo de un zapatero, Calixto Vázquez, que pagaba 45 reales de cuota. Los demás seminaristas de Logroño, cuyas familias hemos podido identificar, a veces con su renta, pertenecen a medios también muy humildes. Celedonio López Castro (de 18 años) es hijo de un cartero, y Narciso Aguileta Salazar (de 20 años) de un labrador. El padre de Miguel Torres Treviño, Manuel, es labrador propietario en el barrio de El Cortijo, pero la modesta contribución territorial que paga dice bien lo mediocre de su fortuna. La única excepción sería Lucas Velasco y Lorza (de 18 años) cuyo padre Francisco Velasco Elías, lencero, parece tener rentas muy confortables y paga una cuota anual de 590 reales $^{12}$.

Esta ojeada, aunque incompleta, confirma el papel desempeñado tradicionalmente por este establecimiento, heredero directo del colegio de jesuitas, en la formación y dirección ideológica de una clase media de modesta renta y origen esencialmente rural.

Llegada la hora de concluir, cabe destacar otra vez el papel del seminario como estructura educativa "de la permanencia», en un contexto socioeconómico decimonónico español profundamente marcado por estructuras tradicionales, heredadas del Antiguo Régimen, y resistencias mentales. El último eslabón de un sistema en el que, por su reclutamiento mayoritariamente humilde y rural, permitía la integración de los hijos de las clases urbanas más desfavorecidas y de algunos campesinos.

Sin embargo bien se intuye, al analizar la documentación local, que el seminario de Logroño, a pesar de haber funcionado hasta 1929, no fue más que un contrapeso algo obsoleto a la novedad, caracterizada por el instituto de segunda enseñanza oficial y sus «satélites» (escuela de dibujo, escuela de arte e industria, colegio politécnico riojano...), en una capital de provincia en la que la nueva burguesía liberal, fruto de una reordenación de las élites del XVIII, había tomado ya el partido del cambio.

11. Benso Calvo, Carmen, "Los destinatarios del bachillerato en Galicia. Estudio geográfico y social del alumnado orensano (1850-1910)", Revista de educación, $\mathrm{n}^{\circ}$ 305, 1994, p. 328, nota 15.

12. Suplemento al Boletín Oficial de la Provincia de Logroño, 30 de abril de 1852, p. $4 ; 7$ de mayo de 1852 , p. 1 ; 9 de mayo de 1852 , p. 1 . 
